de carácter hermenéutico (no instrumentalistas y «racionalistas»); cabe suponer que su reconocimiento posibilitaría la oportunidad de una mayor reflexividad de los expertos y políticos. Así, junto a incorporación de nuevas variables, las nociones reificadas de riesgo, ciencia, sociedad, conocimiento, también requieren un análisis de su constitución y objetivación. Éstas son algunas de las conclusiones que se pueden extraer de las ambivalencias que muestra la gente con los temas relativos a las ciencias.

Una lectura y crítica detenida de estos dos trabajos nos va a servir no sólo para conocer lo que la gente percibe sobre temas de ciencia y tecnología, sino también para una tarea reflexiva: la revisión de los conceptos de ciencia y cultura científica y la indagación de otros determinantes para entender el concepto de «percepciones sociales de la ciencia» resultan una tarea decisiva a tenor de los retos científicos, políticos y cívicos que parecen reabrir las respuestas que ofrece el público.

Andoni EIZAGIRRE

\section{Marta Fraile}

\section{Cuando la economía entra en las urnas. El voto económico en España (1979-1996)}

(Madrid, CIS, Col. Monografías, n. ${ }^{\circ} 217,2005$ )

El voto económico no tiene buena prensa. Recibido como nuevo grial para desentrañar la política de nuestro tiempo, a raíz sobre todo de la primera campaña presidencial de Bill Clinton («es la economía, estúpido»), el público avisado no tardó en percatarse del contrabando de contenidos que traía consigo. Pues, parafraseando el título del libro que nos ocupa, podríamos decir que cuando la economía entra en las urnas... la política sale por la ventana. $Y$ así ocurre que cuando los electores comienzan a fijarse en la economía es frecuente que dejen de lado otras cosas y que los valores que habían brillado con más fuerza en la política, como la ideología y el carisma, queden supeditados a los nuevos imperativos de la imagen de marca y la presentación de una buena cuenta de resultados. Tanto más si, como ha ocurrido en España, el momento de esplendor del voto económico ha venido a coincidir con el esplendor también de la enfebrecida modernidad neocapitalista, con todas sus ofertas y reclamos, desde las rebajas fiscales hasta las privatizaciones de vértigo y las stock options.

Sea como fuere, el voto económico es, como el espectáculo de masas o los desordenados apetitos financieros, un signo de nuestro tiempo y un golpe de tuerca más en el proceso, siempre inconcluso, de racionalización social y política (racionalización del ritual democrático, en este caso). Y para entenderlo nada mejor que el libro de Marta Fraile: Cuando la economía entra en las urnas. El voto económico en España (1979-1996). El libro empieza ofreciendo un marco analítico en el que la autora no se limita a replicar los análisis que con más o menos acierto se han hecho para otros países, sino que va más allá. Éste no es un ejercicio replicante a los que nos tienen acostumbrados tantos análisis contemporáneos, autosatisfe- 
chos por haber repetido para España lo que otros con más originalidad ya habían hecho para EE.UU. o Alemania. Marta Fraile nos propone un modelo de análisis específicamente pensado para el caso español, donde el protagonismo de la oferta política está muy repartido entre las políticas económicas y las políticas de bienestar. Es verdad que algo de esto ya venían diciendo algunos autores desde mediados de los años noventa, cuando llegó a España el primer aluvión de literatura sobre voto económico, pero Fraile ha sabido elevarlo a la categoría de teoría y de modelo analítico empíricamente contrastable.

Vaya por delante que el modelo resiste bien la contrastación. Lamentablemente, el estudio sólo llega hasta las elecciones de 1996, cuando otros análisis de la propia autora al margen del mismo han demostrado fehacientemente que el voto económico en 2000 no hizo más que crecer respecto a cualquier momento de la etapa socialista. Después de todo, ¿qué otra cosa podían votar los electores centrados y pragmáticos en marzo de 2000 que la brillante cuenta de resultados del PP, en medio de una bonanza económica sin precedentes y sin otra preocupación que la del precio político exigido por Jordi Pujol a cambio de su contribución a la gobernabilidad del país?

Hecha esta salvedad, Fraile analiza para cada una de las elecciones generales que van de 1979 a 1996 no sólo los componentes prospectivo y retrospectivo del voto económico, sino también la valoración de las políticas de bienestar y una eventual restricción del voto económico: la credibilidad de la oposición. Pues, a fin de cuentas, de poco sirve que los electores quieran castigar la incompetencia de un gobierno en materia económica si no tienen una mínima garantía de que la oposición lo vaya a hacer mejor. A lo largo de la etapa socialista, Fraile encuentra que el componente prospectivo del voto se debilitó en beneficio del control retrospectivo (los electores cada vez esperaban menos de los socialistas, al tiempo que aumentaba la atribución de responsabilidad sobre éstos), pero el ejercicio del control estaba sujeto a una doble tensión: pues, por un lado, crecían los juicios positivos de las políticas sociales, en tanto que por otro aumentaba, dentro de límites más modestos, la credibilidad de la oposición. Ahora bien, si aumentaban las dos cosas es porque los electores seguían desconfiando de las políticas sociales del PP, de lo que se deduce que si el PP hubiera anticipado en los primeros años noventa las políticas sociales que terminó haciendo una vez que llegó al gobierno (en lugar de amagar con proclamas neoliberales), la etapa socialista hubiera sido seguramente más corta. Dado que el PP se equivocó en este punto, hizo falta que la escandalera de la última legislatura socialista debilitara el efecto de las citadas políticas y reforzara la credibilidad del PP para que éste llegara al gobierno en 1996, tal como apunta el último capítulo del libro.

A lo largo del libro, Marta Fraile aclara y resuelve algunos de los escollos teóricos y empíricos más insidiosos del análisis electoral, como el carácter limitado de la racionalidad de los votantes o el de la causalidad circular entre expectativas económicas y preferencias electorales. En suma, nos encontramos ante un estudio magnífico que no hace sino confirmar la valía de una nueva generación de científicos 
sociales que discurre por sendas de extraordinaria sofisticación metodológica sin sacrificar la pertinencia y la solidez de los problemas planteados.

Juan Jesús GONZÁLEZ

\section{Vidal Díaz de Rada}

\section{Manual del trabajo de campo en la encuesta}

(Madrid, CIS, Col. Cuadernos Metodológicos, n. ${ }^{\circ} 36$,

2005)

Aunque abundan los textos que se ocupan de las distintas fases de la investigación mediante encuesta, son escasas las publicaciones que se centran en aquellos aspectos relacionados con el trabajo de campo, con la recogida de la información de la entrevista personal. El Cuaderno Metodológico n. ${ }^{\circ} 36$ del Centro de Investigaciones Sociológicas nos ofrece la oportunidad de profundizar en este tema.

Desde que se inició la colección, que tan buena acogida ha tenido entre investigadores, profesores y alumnos de sociología, han tenido que pasar muchos años para ver materializada una guía que sirva de modelo tanto a los responsables de las redes de campo como a los entrevistadores. $Y$ éste es el caso del manual de Vidal Díaz de Rada. Un libro en el que se dan indicaciones sobre la forma de actuar de unos y otros.
El propósito central de esta obra es enseñar al futuro entrevistador cuáles son sus funciones básicas antes, durante y después de la entrevista. Asimismo, el autor aclara conceptos y situaciones con frecuencia olvidadas por aquellos que se dedican a la práctica de la encuesta. En algunas ocasiones, la ambición investigadora lleva a plantear cuestionarios difícilmente aplicables a una población a la que cada día es más difícil acceder y convencer de participar en un estudio.

Este trabajo de Díaz de Rada está muy centrado en la forma de trabajar del Centro de Investigaciones Sociológicas. No obstante, no olvida en el capítulo 2 ofrecer una visión comparada con el INE y otras instituciones e institutos de investigación social y de mercado. Cuando se refiere a la selección de las viviendas y de las personas que han de formar parte de la muestra, nos recuerda que la disponibilidad de un marco muestral completo - censo o padrónfacilita la selección nominal de los posibles encuestados. Sin embargo, tanto el CIS como el IESA y los institutos de opinión privados utilizan marcos muestrales incompletos, lo que les lleva a desarrollar otros procedimientos de selección: recuento exhaustivo de los residentes, rutas aleatorias, rutas con elección de alternativas mediante tablas de números aleatorios y sistema de rutas en zigzag.

Este segundo capítulo, el más largo del libro, podría resultar algo tedioso en su lectura por lo exhaustivo si no fuera porque nos acerca a las distintas formas de trabajar de las mencionadas instituciones, valorando las ventajas e inconvenientes de utilizar un marco muestral u otro. Si la recogida de datos no persigue resul- 